$\mathrm{X}$.

Aus der medicinischen Klinik der Akademie für praktische Medicin zu Düsseldorf (Director: Prof. Dr. A. Hoffmann).

\title{
Vergleichende Untersuchungen über den Eiweissgehalt des capillaren und venösen Blutserums bei gesunden und kranken Menschen.
}

\author{
Von \\ Walter Baggerd, \\ Medicinalpraktikant.
}

Durch die Arbeiten von Strubell (1), Grober (2), Reiss (3-6), Strauss $(7-8)$ u. a. ist ein neues Verfahren bekannt geworden, Eiweissbestimmungen des Blutserums auf einfache und dabei doch relativ zuverlässige Weise durch die Untersuchung des Brechungsvermögens des Blutserums für einfallende Lichtstrablen $\mathrm{zu}$ bestimmen. Es liegt auf der Hand, dass sich die klinische Medicin bemühen muss, diese Arbeitsmethode weiter auszubilden, wenn es sich zeigen sollte, dass der Eiweissgehalt des Blutserums diagnostische Wichtigkeit besitzt, d. h. wenn sein Werth bei bestimmten Krankheiten ein approximatives Fixum aufweist.

Die Frage nach dem brechenden Werth einer 1 proc. Eiweisslösung - die die procentuale Summation der Eiweisskörper des Blutserums enthält - ist von Reiss gelöst worden. Jedoch ist diese, durch einfache Versuchsanordnung festzustellende Zahl, nur dann von Werth, wenn die anderen Momente, die im Blutserum die Ablenkung des Lichtstrahles bedingen, absolute oder doch fast absolut feststehende sind. Auch diese Frage hat Reiss gelöst. Er fand nämlich, dass die Nichteiweisskörper des Serums einen Brechungsindex von 0,00277 aufweisen. Die brechende Kraft der restirenden Flüssigkeit ist dann der des destillirten Wassers gleichzusetzen und beträgt 1,33320. Jede Ueberschreitung der Summe der Nichteiweisskörper und der restirenden Flüssigkeit, also von 1,33597 ist also auf das in dem Serum enthaltene Eiweiss zu beziehen. Die Richtigkeit dieser Ueberlegung ist von Reiss durch zahlreiche Versuche bestätigt worden, indem er einerseits den Eiweissgehalt durch Fällung und Wägung und andererseits durch die refractometrische Methode bestimmte. Die Unterschiede, die hierbei zu Tage traten, waren nur unerhebliche, so dass wir mit dieser Methode hinsichtlich ihrer Genauigkeit völlig zufrieden sein können.

Die zweite Frage, die beantwortet werden muss, ehe wir an eine systematische Bestimmung des Blutserumeiweiss gehen können, ist die, ob wir bei gesunden Menschen überhaupt feststehende Zahlen des Eiweissgehaltes finden, und ob eine Unter- resp. Ueberschreitung dieses Werthes durch pathologisehe Veränderungen des Organismus bedingt werden. Reiss ist zu dem Ergebniss gekommen, dass sich bei normalen Menschen die 
Werthe zwischen 56-64 der Scala des Pulfrich'schen Refractometers bewegen. Diese Zahlen entsprechen einem Brechungsindex von 1,34873 bis 1,35168, oder einem Eiweissgehalt von 7,42 bis 9,13 pCt. Nach seinen Resultaten hat Reiss (9) eine Tabelle ausgearbeitet, welche es ermöglicht, den Brechnungsindex leicht in die Procentzahl des Eiweissgehaltes umzurechnen. Diese Tabelle dient mir bei folgenden Untersuchungen.

Von vornherein sei darauf hingewiesen, dass es nicht gleichgültig ist, ob wir das Blut aus der Fingerbeere, dem Obrläppchen usw., d. b. aus dem capillaren Gebiet, oder aus der Vene direct entnehmen. Es haben sich bei meinen Versuchen fast immer Unterschiede gefunden, die insofern keine Gleichsinnigkeit zeigen, als bisweilen der Eiweissgehalt des venösen Blutes, bisweilen der des capillaren Blutes höhere Werthe ergab. Jedoch scheint es, dass normaler Weise der Brechnungsindex des capillaren Blutes höhere Werthe ergiebt, als der des venösen.

Tabelle 1 .

\begin{tabular}{|c|c|c|c|c|c|c|c|c|c|c|c|c|}
\hline & \multirow{2}{*}{$\stackrel{\overrightarrow{0}}{\stackrel{\vec{\Xi}}{二}}$} & \multirow{2}{*}{$\begin{array}{l}\text { Blut- } \\
\text { druck }\end{array}$} & \multirow{2}{*}{ 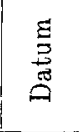 } & \multirow[b]{2}{*}{ Zeit } & \multicolumn{3}{|c|}{$V \in n e$} & \multirow[b]{2}{*}{ Zeit } & \multicolumn{3}{|c|}{ Capillare } & \multirow{2}{*}{$\begin{array}{l}\text { Unter- } \\
\text { schied }\end{array}$} \\
\hline & & & & & Skala & $\mathrm{nD}$ & $\begin{array}{c}\text { Eiweiss } \\
\text { pCt. }\end{array}$ & & Skala & $\mathrm{nD}$ & $\begin{array}{c}\text { Eiweiss } \\
\text { pCt. }\end{array}$ & \\
\hline $\begin{array}{l}\text { H., weibl., trau- } \\
\text { matische Neurose }\end{array}$ & 52 & $190: 125$ & 5.2. & 110 & 60,4 & 1,350358 & 8,3656 & $1^{13}$ & 60,0 & 1.350210 & 8,2800 & 0,0856 \\
\hline $\begin{array}{l}\text { B., weibl.,ges. Mensch } \\
\text { Sch,, weibl., Aortitis }\end{array}$ & 25 & $175: 110$ & 15.2. & $10^{1}$ & 56,4 & 1,348878 & 7,5024 & $10^{12}$ & 56,1 & 1,348767 & 7,4376 & 0,0678 \\
\hline B., weibl., Rheuma- & 44 & $195: 110$ & 8. 2 . & 945 & 56,4 & 1,348878 & 7,5024 & $9^{47}$ & 55,85 & 1,348674 & 7,3836 & 0,1188 \\
\hline tismus & 36 & $180: 130$ & 8. 2. & 1015 & 66,0 & 1,352420 & 9,5620 & $10^{19}$ & 64,3 & 1,351801 & 9,2002 & 0,3618 \\
\hline $\begin{array}{l}\text { P., welbl., Iscmas } \\
\text { B., weibl., ges. Mensch }\end{array}$ & $\begin{array}{l}00 \\
25\end{array}$ & $\begin{array}{l}105: 110 \\
165: 100\end{array}$ & $\begin{array}{r}\text { 6. } 4 . \\
16.2 .\end{array}$ & $\begin{array}{c}12 \\
9^{15}\end{array}$ & $\begin{array}{l}60,4 \\
56,4\end{array}$ & $\begin{array}{l}1,350358 \\
1,348878\end{array}$ & $\begin{array}{l}8,5656 \\
7,5024\end{array}$ & 916 & $\begin{array}{l}60,4 \\
56,0\end{array}$ & $\begin{array}{l}1,300000 \\
1,348730\end{array}$ & $\begin{array}{l}0.5000 \\
7,4160\end{array}$ & 0,0864 \\
\hline D., weibl., Cholangitis & 66 & $160: 85$ & 4.5. & 1150 & 57,6 & 1,349322 & 7,7616 & $11^{52}$ & 57,3 & 1,349211 & 7,6968 & 0,0648 \\
\hline
\end{tabular}

Tabelle I zeigt fast überall in dem Venenblut einen höheren Eiweissgehalt wie in dem Capillarblut:. Gerade ein umgekehrtes Verhalten ergiebt sich aus Tabelle $1 \mathrm{I}$.

Tabelle 11 .

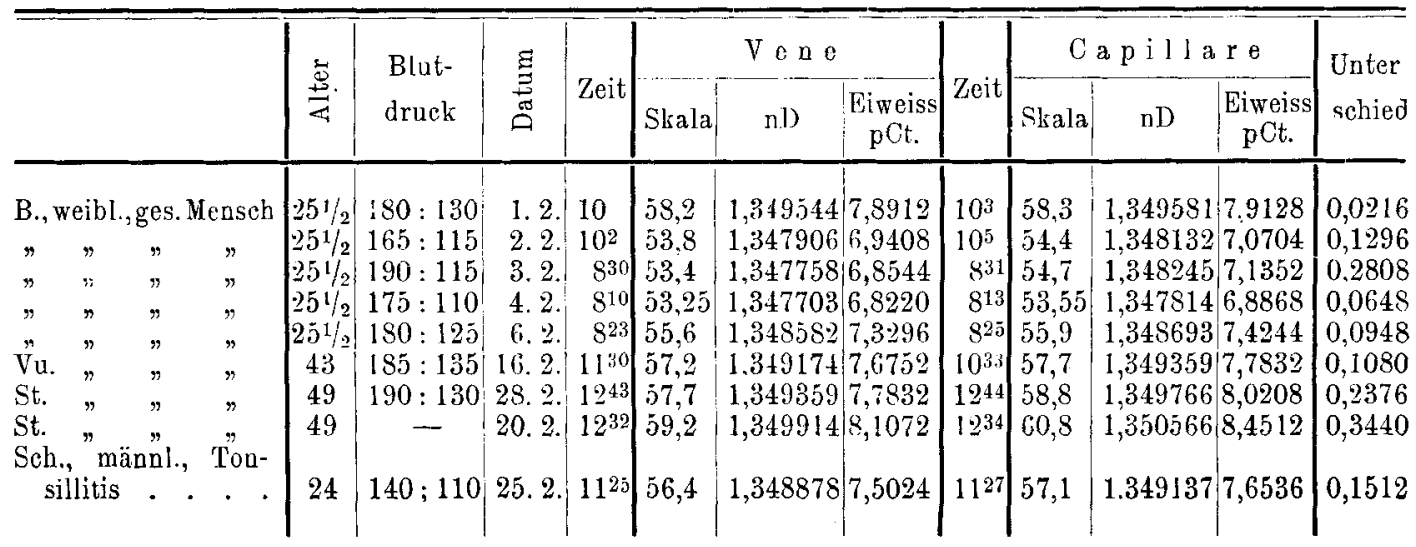


Diese Unterschiede könnton nun daran liegen, dass bei der Blutentnahme eine gewisse, nicht zu controllirende Stauung angewendet wurde. Ich habe deshalb Versuche angestellt, um diese Fehlerquelle auszuschalten. Der Gang der Versuche war folgender.

Aus einer ungestanten Vene wurde mittejs Spritze Blut entnommen. Sofort darauf wurden, ohne Anwendung irgend welchen Druckes einige Tröpfchen Blut aus dem Ohrläppchen resp. aus dem Finger gewonnen und zwar wurden sie bei dem Hervorquellen in U-förmig gebogene Röhrchen aufgesogen. Diese Glasröhrchen wurden sodann paraffinirt und so lange centrifugirt, bis sich das Blutserum klar abgesetzt hatte. Es sei noch darauf hingewiesen, dass die Blutentnahme ohne jede Desinfection der Haut gemacht wurde, weil nach den Erfahrungen von v. d. Velden (10) u. a. schon kurze mechanische wie chemische Reize eine sofortige locale Veränderung dor Blutdichte zur Folge haben können. Auch jetzt stellten sich Unterschiede zwischen dem Eiweissgehalt des venösen und capillaren Blutserums heraus.

Tabelle III.

\begin{tabular}{|c|c|c|c|c|c|c|c|c|c|c|c|c|}
\hline & \multirow{2}{*}{ 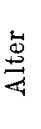 } & \multirow{2}{*}{$\begin{array}{l}\text { Blut- } \\
\text { druck }\end{array}$} & \multirow{2}{*}{ 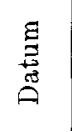 } & \multirow{2}{*}{ Zeit } & \multicolumn{3}{|c|}{$V$ ene } & \multirow{2}{*}{ Zeit } & \multicolumn{3}{|c|}{ Capillare } & \multirow{2}{*}{$\begin{array}{l}\text { Unter- } \\
\text { schied }\end{array}$} \\
\hline & & & & & Skala & $\mathrm{nD}$ & $\begin{array}{l}\text { Eiweiss } \\
\text { pCt. }\end{array}$ & & Shala & $\mathrm{nD}$ & $\begin{array}{c}\text { Eiweiss } \\
\text { pCt. }\end{array}$ & \\
\hline \multirow{3}{*}{$\begin{array}{l}\text { F., weibl., Angina - } \\
\text { Sch., männl., Chole- } \\
\text { lithiasis. . } \\
\text { M., männl., Gastritis } \\
\text { abgelaufen) }\end{array}$} & 29 & $200: 135$ & 19.2. & $4^{18}$ & 55,8 & 1,348656 & 7,3728 & $4^{12}$ & 58,2 & 1,349544 & 7,8912 & $0,5154 ! !$ \\
\hline & 32 & $220: 110$ & 9.6 . & 1230 & 59,5 & 1,350025 & 8,1720 & $12^{33}$ & 60,4 & 1,350358 & 8,3656 & 0,1936 \\
\hline & & & 20. & & & & & & & & & \\
\hline $\begin{array}{l}\text { (abgelaufen) } \\
\text { B., weibl., Muskel- }\end{array}$ & 36 & $175: 105$ & 9.6. & $12^{38}$ & 59,9 & 1,350173 & 8,2584 & 1240 & 60,1 & 1,350247 & 8,3014 & 0,0130 \\
\hline zerrung. '. & 42 & $170: 100$ & 9.6 . & 1253 & 56,2 & 1,348804 & 7,4592 & 1255 & 56,6 & 1,348952 & 7,5456 & 0,0864 \\
\hline $\begin{array}{c}\text { D., welol., Neur- } \\
\text { asthenie . }\end{array}$ & 24 & $185: 105$ & 14.2. & 457 & 56,7 & 1,348989 & 7,5672 & $4^{5 i}$ & 56,3 & 1,348841 & 7,4808 & 0,0864 \\
\hline $\begin{array}{c}\text { P., weibl., Neur- } \\
\text { asthenie }\end{array}$ & 56 & $210: 130$ & 5.4 . & $11^{42}$ & 59.5 & 1,350025 & 8,1720 & 1143 & 60,7 & 1.350469 & 8,4299 & $0,2578 ! !$ \\
\hline H., männl., prog. & 35 & 175.120 & & & & & & & & & & \\
\hline Muskelatrophe . & 00 & {$[10: 120$} & o. 4. & $12^{6}$ & 60,4 & 1,350358 & 8,3656 & 123 & 60,4 & 1,350388 & 8,3656 & 0,0000 \\
\hline
\end{tabular}

Wir sehen also, dass nicht die Stauung die Schwankungen in den Werthen des capillaren und venösen Serums bewirken kann. Die Ursachen können verschiedene andere sein. Eine derselben liegt in der Vermischung des capillaren Blutes mit Zellsaft, der sich aus den angeschnittenen Zellen und Lymphspalten den hervorquellenden Blute beimischt. Diese Beimengung kann, wenn es sich, wie bei obigen Versuchen, um normalen Turgor der Gewebe handelt, nicht allzu gross sein, da die Unterschiede, die wir im Eiweissgehalt des venösen und capillaren Blutes gefunden haben, nur geringe sind. Ganz anders gestaltet sich die Frage bei Oedemen. Von vorn herein ist es unwahrscheinlich, dass überall dort, wo sichtbare Oedeme vorhanden sind, auch eine erhöhte Turgescenz der gesammten Gewebe des Organismus vorhanden ist. Entnehmen wir nun das Blut der Vene selbst, so bildet dieser erhöhte Turgor keine Fchlerquelle bei der Eiweissbestimmung. $\Lambda$ nders ist es aber bei der Blutgewinnung aus dem capillaren System. 
Hier wird natürlich um so mehr Zellsaft und Lymphflüssigkeit dem hervorquellenden Blute beigemischt, je hochgradiger die localen Oedeme sind. Dass hierdurch die Eiweissbestimmung relativ hohen Fehlerquellen unterliegt, dürften folgende angezogene Werthe bestätigen, die bei ödematösen Menschen gewonnen sind.

Tabelle IV.

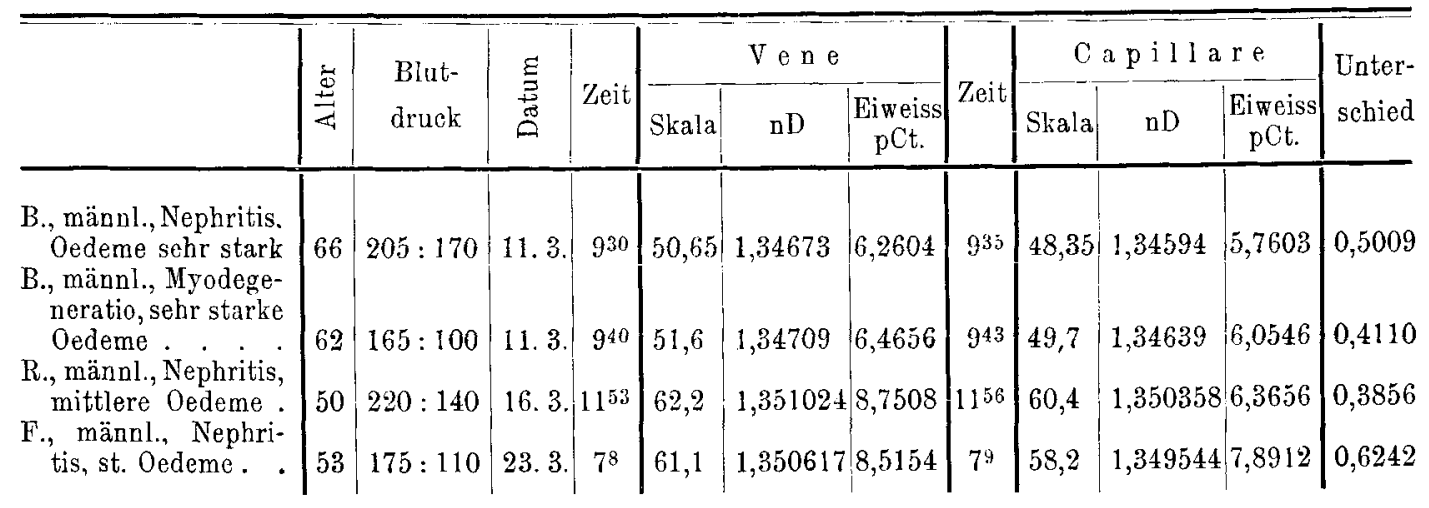

Wir sehen aus diesen Versuchen, dass es doch von Wichtigkeit ist, diese eventuelle Verdünnung des Blutes mit Gewebssaft in Rechnung zu ziehen. Es dürfte sich deshalb empfehlen, bei Menschen mit Oedemen auf die sonst so zweckmässige Blutentnahme aus der Fingerbeere zu verzichten und lieber eine Venenpunction vorzunehmen. Ob wir dabei nun kurz dauernde Stauung anwenden oder ob wir das Blut direct ohne Staung aus der Vene mit der Spritze entnehmen, ob wir leicht desinficiren, macht nach meinen Erfahrungen kaum irgend welchen grösseren Effect auf das Resultat der Eiweisbestimmung aus. Trotzdem sind die späteren Versuche fast ausnahmslos ohne Anlegung einer Gummibinde nach leichter Desinfection der Haut gemacht worden.

Die anderen Factoren, die den Unterschied des Eiweissgehaltes des venösen und des capillaren Blutes bedingen, liegen in den physikalischen und chemischen Vorgängen im Capillarsystem. Hier tritt ein Flüssigkeitsaustausch zwischen Blut und Geweben ein, indem einerseits Ernährungsflüssigkeit aus den Capillaren in die Gewebe diffundirt, andererseits aber auch umgekehrt aus den umliegenden Geweben Flüssigkeit zurückresorbirt werden kann. Dass hierdurch eine Verdünnung resp. Eindickung des capillaren gegenüber dem venösen Blute eintreten kann, ist klar. Dieser Flüssigkeitsaustausch ist abhängig von den Gesetzen der Lehre von der Osmose und der Filtration. Während erstere bedingt ist durch die Concentrationsschwankungen zwischen Blut und Gewebsflüssigkeit, ist letztere im Grunde wohl nur beeinflussbar durch die Durchlässigkeit der trennenden Wand und den Druckunterschieden der beiden Medien. Nehmen wir den Druck ausserhalb des Gefässsystems zunächst als constant an, so ist die Filtration wohl hauptsächlich durch den Blutdruck, d. h. durch die Relation der Weite der Gefässe und der Vis a tergo bedingt. Es ist von verschiedener Seite die Einwirkung von Druckschwankungen im Gefässsystem auf die 
Concentration des Blutes untersucht worden. Hierbei hat sich gezeigt, dass eine Erhöhung des Blutdruckes mit Concentrationssteigerung, dass hingegen mit dem Sinken des Blutdruckes eine Abnahme der Concentration Hand in Hand geht. Diese Ergebnisse, die durch Zählungen der rothen Blutkörperchen, durch Bestimmungen des Stickstoffgehaltes usw. gewonnen wurden, sind durch Diffusion von Blutflüssigkeit ins Gewebe resp. durch Resorption ins Gefässsystem erklärt worden. Es lässt sich bei diesen Untersuchungen wohl annehmen, dass wir diese Schwankungen der Concentration als relative Veränderungen aufzufassen haben, da es kaum möglich erscheint, dass durch die angewandten experimentellen Methoden wie heisse Bäder [Grawitz (11)], Durchwärmung von Kaninchen mittels heisser Luft [Loew y (12)] usw. absolute Aenderungen im Eiweissgehalt des Serums eintreten könnten.

Bei unseren Versuchen haben wir nun fast regelmässig einen Unterschied im Eiweissgehalt des capillaren und venösen Serums gefunden, da nämlich bisweilen der Brechungsindex in ersterem, bisweilen in letzterem überwog. Es liess sich kein directer Einfluss des Blutdruckes nachweisen (gemessen mit der v. Recklinghausen'schen Apparatur am Oberarm), da z. B. in Tabelle 1 Fall No. 3 und $\bar{y} z$ war fast denselben Eiweissgehalt, aber ganz verschiedenen Blutdruck aufweisen. Gerade bei Fall No. 3, der einen Blutdruck von nur 160:60 $\mathrm{cm}$ Wasser rach von Recklinghausen zeigt, müsste ja nach den obigen Versuchen von Grawitz und Loewy eine Verdünnung des Blutes im Capillarsystem eintreten, was mit dem höher liegenden Werth des Venenblutes nicht in Einklang zu bringen ist. Es fragt sich nun, ob wir auch hier nur eine relative Veränderung des Gehaltes an Eiweiss im venösen resp. capillaren Blute vor uns haben, oder ob wir nicht gleichzeitig mit den rolativen Schwankungen des Eiweissgehaltes eine Aenderung des absoluten Werthes annehmen müssen. Wenn wir im capillaren Serum gegenüber dem venösen einen höheren Eiwejssgehalt finden, so kann das daran liegen, dass aus der Umgebung Gewebsflüssigkeit in die Gefässe zurückresorbirt wird, zumal wir ja nicht wissen, ob wir bei der Blutentnahme in der Hauptsache venöse oder arterielle Gefässe anstechen, andererseits kann der Grund darin zu suchen sein, dass bei dem Passiren des Blutes in den feinsten Capillaren ein Verbrauch von Eiweiss eintritt. Wenngleich die gefundenen Werthe bei normalen Menschen nur wenig differiren, so müsste bei dem geringen Unterschiede des Gehaltes an Eiweiss zwischen Blut und Gewebsflüssigkeit doch eine relativ grosse Menge verdünnenden Gewebsaftes für einen solchen Unterschied verantwortlich gemacht werden. Dass aber bei normalen Menschen die Rückresorption in das Capillarsystem nicht so hochgradig sein kann, ist mindestens wahrscheinlich. Dieser Erklärungsversuch, dass es sich bei dem Passiren des Blutes im Capillarsystem um einen Eiweissverbrauch handelt, kann aber nur dann verständlich sein, wenn wir einen Unterschied des Eiweissgehaltes im arteriellen und venösen Blutes finden und zwar zu Ungunsten des venösen. Der Schwierigkeit wegen, arterielles Blut von Menschen zu gewinnen, sind dic folgenden Versuche an Kanin- 
chen angestellt worden. Es handelte sich um ausgewachsene, gesunde Thiere. Die gefundenen Werthe sind auf folgender Tabelle angegeben.

Tabelle V.

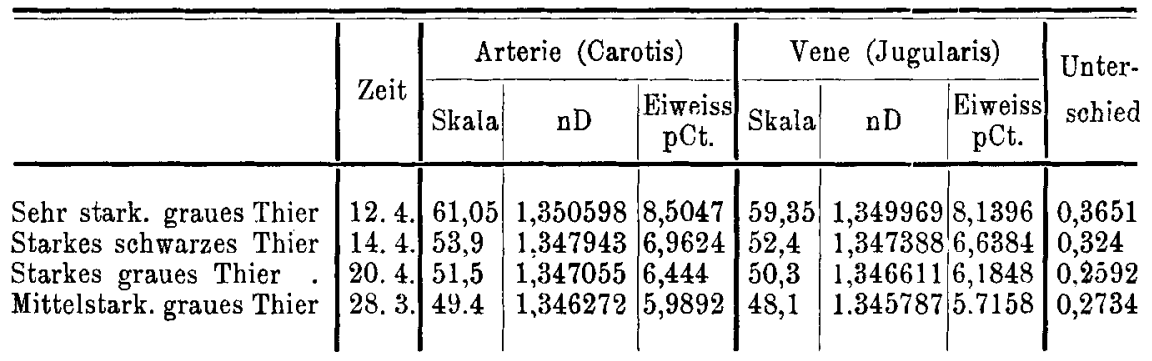

Wir sehen also in der That, dass das arterielle Blut einen höheren Eiweissgehalt aufweist als das venöse. Die gefundenen Unterschiede liegen doch so hoch, dass sie nicht einfach durch eine Verdünnung im capillaren System durch Rückresorption erklärt werden können, sondern es wird wohl das im Blutserum enthaltene Eiweiss durch die Capillarwand hindurch an die Zellen des Gewebes herantreten.

Was nun zunächst die Werthe, die bisher bei gesunden Menschen gefunden worden sind, betrifft, so kann ich bei meinen Untersuchungen die von Reiss als Normalwerthe aufgestellten Zahlen (56 der Scala = 7,42 pCt. Eiweiss $-64=9,13$ pCt. Eiweiss) nur bestätigen. Doch ist es von vorn herein falsch, bei Werthen, die sich etwas unterhalb der Normalgrenze bewegen, ohne Weiteres eine pathologische Verdünnung annehmen zu wollen. Nach sehr starker Flüssigkeitsaufnahme habe ich im Einklang mit Strauss-Chajes und Chiaorlanza (13) bei sonst normalem Eiweissgehalt des Blutes herabgesetzte Werthe gefunden, die in einem Falle bis 6,68 pCt. Eiweiss herabgingen. Deshalb ist es von Wichtigkeit, bei der Blutuntersuchung auf die vorangegangene Flüssigkeitsaufnahme zu achten, weil sonst falsche Schlüsse möglich sind. Jedenfalls muss uns die Eiweissbestimmung des Blutserums eine Antwort auf die Frage der Serumconcentration im Allgemeinen geben. Stellt es sich heraus, dass der brechende Index niedrig liegt, so dürfte der Schluss wohl berechtigt sein, dass wir in diesem Falle eine acute resp. chronische Verdünnung des Blutes vor uns haben, dass wir also den Krankbeitsbegriff der Hydrämie durch die refractometrische Blutuntersuchung leicht sicher erkennen können. Es liesse sich vielleicht hier die Erage aufwerfen, ob nicht eventuell ein niedrig liegender Werth der Eiweissconcentration auf eine von verschiedenen Autoren angenommene, und bei einzelnen Krankheiten wahrscheinlich bestehende Oligaemia vera zu beziehen ist, weil die Möglichkeit nicht von der Hand zu weisen ist, Jass bei consumirenden Krankheiten auch das Organ Blut in allen seinen Bestandtheilen den consumirenden Einflüssen der Krankheit anheimfällt. Diese Frage lässt sich jedoch erst dann einheitlich entscheiden, wenn es uns gelingt, eine einigermassen sichere Methode zu finden, um die Gesammtmenge des menschlichen Blutes zu bestimmen. 


\section{Untersuchungen des Eiweissgehaltes des Blutserums bei Erkrankungen der Kreislauforgane.}

Dass bei Decompensation des Kreislaufes der Eiweissgehalt des Blutserums im Allgemeinen vermindert ist, haben bereits 1844 Becquerel und Rodier (14) gefunden. Diese Thatsache, die hier zum Theil ebenfalls wieder bestätigt werden kann, beruht nun entweder auf der Möglichkeit, dass zu wenig Flüssigkeit durch die Nieren ausgeschieden wird, oder dass ein Volumen auctum der Blutmenge eintritt. Die letztere Ansicht ist von Stintzing und Gumprecht (15) vertreten worden. Die Erklärung für diese Erscheinung giebt Grawitz (11). Nach ihm ist der wichtigste Moment die Herabsetzung des Blutdruckes, mit der eine Dilatation der Capillaren Hand in Hand geht. Die in ihrem Querschnitt somit vergrösserten Gefässe füllen dann durch Aufnahme von Gewebssaft ihren Inhalt wieder auf. Hierdurch muss natürlich eine Verdünnung des Blutes im Allgemeinen entstehen, die allerdings, wie früher ausgeführt wurde, wegen des Eiweissgehaltes der Gewebsflüssigkeit, der nur wenig niedriger liegende Werthe wie im Blutserum aufweist, nur gering sein kann. Bei chronischen Stauungserscheinungen, die auf Herzfehlern beruhen, soll die Herabsetzung des Eiweissgehaltes nach Grawitz neben der Hydrämie in der chronischen Unterernährung seinen Grund haben, da „diese Kranken häufig wegen starker Appetitlosigkeit und der Stauungen in der Magenschleimhaut lange Zeit hindureh ungenügende Mengen von Nährstoffen in sich aufnehmen". Entgegen früherer Anschauung, dass das Blut im capillaren System wasserreicher sei als im venösen, ist bei chronischen Stauungszuständen die Concentration und die Zahl der rothen Blutkörperchen im venösen geringer als im capillaren Blute.

Die Ergebnisse meiner Untersuchung über den Eiweissgehalt des Blutserums bei compensirten und decompensirten Herzfehlern sind in den folgenden Tabellen zusammengestellt.

Tabelle VI.

\begin{tabular}{|c|c|c|c|c|c|c|c|c|c|c|c|c|}
\hline & \multirow{2}{*}{$\stackrel{\dddot{\Phi}}{\Xi}$} & \multirow{2}{*}{$\begin{array}{l}\text { Blut- } \\
\text { druck }\end{array}$} & \multirow{2}{*}{ 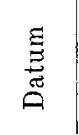 } & \multirow[b]{2}{*}{ Zeit } & \multicolumn{3}{|c|}{$V$ e ne } & \multirow[b]{2}{*}{ Zeit } & \multicolumn{3}{|c|}{ Capillaro } & \multirow{2}{*}{$\begin{array}{l}\text { Unter- } \\
\text { schied }\end{array}$} \\
\hline & & & & & Skala & $\mathrm{nD}$ & $\begin{array}{c}\text { Eiweiss } \\
\text { pCt. }\end{array}$ & & Skala & $\mathrm{nD}$ & $\mid \begin{array}{c}\text { Eiweiss } \\
\text { pCt. }\end{array}$ & \\
\hline L., männl., Mitral- & 34 & 155 & 34 & 118 & 613 & 135069 & 8.5582 & 1110 & 63,5 & 13551505 & 9029 & 0.4708 \\
\hline $\begin{array}{l}\text { B., männl, Mitral- } \\
\text { insufficienz. . : }\end{array}$ & 16 & $140: 95$ & 3.3 . & $11^{13}$ & 59,45 & 1,35000 & 8,1612 & $11^{14}$ & 61,1 & 1.350697 & 8,5154 & 0,3542 \\
\hline $\begin{array}{l}\text { Sch., weibl., Stenose } \\
\text { u. Insufficienz }\end{array}$ & 42 & $170: 130$ & 4. 3. & $11^{17}$ & 60,4 & 1,35036 & 8,37 & 1120 & 61,1 & 1,350627 & 8,5154 & 0,1454 \\
\hline $\begin{array}{l}\text { 0., weibl., Aorten- } \\
\text { vitium }\end{array}$ & 22 & $155: 125$ & 4. 3. & 147 & 53,7 & 1,347864 & 6.9192 & 149 & 55,25 & 1,348352 & 7,254 & 0,3058 \\
\hline $\begin{array}{l}\text { P., männl., Mitral- } \\
\text { insufficienz . } \\
\text { F. männl. Mitral- }\end{array}$ & 52 & $180: 115$ & 16.5 . & 917 & 56,9 & 1,349063 & 7,6104 & 919 & 57,3 & 1,349211 & 7,6968 & 0,086 \\
\hline $\begin{array}{l}\text { insufficienz : } \\
\text { Sch., männl., Insuffi- }\end{array}$ & 36 & $130: 70$ & 16.5. & 923 & 58,4 & 1,349618 & 7,9344 & 925 & 59,0 & 1,349840 & 8,1540 & 0,2196 \\
\hline cienz u. Stenose. & 38 & $185: 95$ & 16.5. & $9+3$ & 61,9 & 1,350913 & 8,6866 & 944 & 61,9 & 1,350913 & 8,6866 & 0,0000 \\
\hline K., männl., Stenose & 41 & $150: 90$ & 16.5. & $9^{34}$ & 58,2 & 1,349544 & 7,8912 & $9^{36}$ & 57,2 & 1,349174 & 7,6752 & $0,2160 !$ \\
\hline
\end{tabular}


Tabelle VII.

\begin{tabular}{|c|c|c|c|c|c|c|c|c|c|c|c|c|}
\hline & \multirow{2}{*}{ 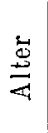 } & \multirow{2}{*}{$\begin{array}{l}\text { Blut- } \\
\text { druck }\end{array}$} & \multirow{2}{*}{ 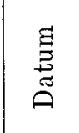 } & \multirow[b]{2}{*}{ Zeit } & \multicolumn{3}{|c|}{$\mathrm{Vene}$} & \multirow[b]{2}{*}{ Zeit } & \multicolumn{3}{|c|}{ Capillare } & \multirow{2}{*}{$\begin{array}{l}\text { Unter- } \\
\text { schied }\end{array}$} \\
\hline & & & & & Skala & $\mathrm{nD}$ & Eiweiss & & Skala & $\mathrm{nD}$ & $\begin{array}{l}\text { Eiweiss } \\
\text { pCt. }\end{array}$ & \\
\hline $\begin{array}{l}\text { Scb., männl., Aorten- } \\
\text { insuffic., Oedeme }\end{array}$ & 45 & $200: 120$ & $4,4$. & $2^{39}$ & 49,0 & $\mid 1,346120$ & 5,9020 & $2^{40}$ & 50,3 & 346611 &, 1848 & $0,282 \mathrm{~S}$ \\
\hline $\begin{array}{l}\text { K., männI., Insuffic., } \\
\text { Oedeme. . . }\end{array}$ & 38 & $250: 200$ & 3.4 . & $10^{50}$ & 50,0 & 1,346500 & 6,1200 & $10^{52}$ & 52,2 & 1,347314 & $\begin{array}{l}4,5952 \\
6,592\end{array}$ & 0,4752 \\
\hline $\begin{array}{l}\text { S., männl., Insuffic., } \\
\text { Pleuritis, Oedeme }\end{array}$ & 68 & $220: 146$ & 3.4 . & $11^{30}$ & 58,5 & 1,349655 & $\begin{array}{l}57,956 \\
\end{array}$ & $11^{32}$ & 60,9 & 1,350543 & 38,4626 & 0,5066 \\
\hline $\begin{array}{c}\text { Sch., weibl., Insuffic., } \\
\text { Oedeme. . . }\end{array}$ & 45 & $200: ?$ & 3.4 & $11^{24}$ & 52,5 & $|1,347425|$ & $\begin{array}{ll}5 & 6,660\end{array}$ & 1126 & 54,8 & 1,348276 & 67,1568 & 0,4968 \\
\hline $\begin{array}{l}\text { K, männl., Insuffic., } \\
\text { Oedeme. }\end{array}$ & 51 & $230: 140$ & 27.3. & $10^{25}$ & 46,5 & 1,345185 & \begin{tabular}{|l|l}
5 & 5,357
\end{tabular} & $10^{30}$ & 48,2 & 1,345824 & 45,7276 & 0,3706 \\
\hline W., weibl., Stenose, & 44 & $160: 105$ & 3.4 . & $10^{17}$ & 51,2 & 1,346944 & $4|6,3792|$ & $10^{40}$ & 51,4 & 1,347018 & 86,4924 & 0,0432 \\
\hline $\begin{array}{l}\text { B., weibl., Insuffic., } \\
\text { Hydrothorax, Oed. }\end{array}$ & 49 & $150: ?$ & 3. 4 . & 1210 & 52,5 & $\mid 1,347425$ & $5,6,660$ & 1240 & 50,8 & 1,346796 & $6 \mid 6,2928$ & $0,3672 !$ \\
\hline
\end{tabular}

Wir sehen bei diesen, nach klinischer Auffassung compensirten Herzfehlern, dass wir eine höhere Concentration im capillaren Blute gegenüber dem venösen Blute haben. Relativ selten sind umgekehrte Verhältnisse gefunden worden. Ich bin geneigt, ein solches Verhalten auf mögliche Fehlerquellen zu beziehen. Diese Erscheinung, dass das capillare Blut einen höheren Brechungsindex als das vonöse aufweist, kann nur darauf beruhen, dass das Blut im Capillarsystem verdünnt oder Eiweiss in vermehrter Menge ins Gewebe abgegeben wird. Letztere Annahme ist nicht von der Hand zu weisen, wenn man sich die starke Durchlässigkeit der Gefässwände für Eiweiss bei Herzinsufficienzen in anderen Gebieten, d. h. in der Niere, ins Gedächtnis ruft.

Demnach könnte die Concentration des capillaren Blutes um so höher sein gegenüber dem venösen, je hochgradiger die Insufficienz des Herzens. Die folgenden Versuche, die bei acuten resp. bei chronischen Insufficienzen vorgenommen sind, sollen uns auf diese Frage eine Antwort geben. Es sind hierbei aus der Tabelle die Fälle ausgeschaltet, welche durch starke Digitalisgaben im Beginn der Compensation standen.

Versuch 4 ist angeführt worden, weil das Blut aus der Vene bei Gelegenheit einer Venensection entnommen worden ist. Es wurden hierbei $450 \mathrm{ccm}$ Blut ablaufen gelassen. Die capillare Bcstimmung des Eiweisses erfolgte eine halbe Stunde später. Wir sehen, dass sich das Blutserum in dieser Zeit so weit aus den Wasserdepots aufgefüllt hat, dass eine sehr deutliche Verdünnung selbst im capillaren Blute eingetreten ist.

Die anderen angeführten Fälle zeigen eigentlich keine merklich höberen Unterschiede im Eiweissgehalt des capillaren und venösen Blutes, wie die Versuche bei compensirten Herzfehlern. Das Resultat müsste also, bei der relativ hochgradigen Stauung, eigentlich gegen den obigen Erklärungsversuch sprechen. Erinnern wir uns aber der früher unternommenen Versuche, die bei Oedemen in Folge von Nephritis, und bei 
andersartigen Oedemen vorgenommen wüden, so wissen wir, dass anormal viel Gewebsflüssigkeit dem capillaren Blute bei der Entnahme beigemengt, und dass sein Eiweissgehalt dadurch horabgesetzt wird. Wenn wir diese Verhältnisse beachten, so ist es klar, dass die Ergebnisse der Bestimmung des capillaren Eiweissgehaltes um wenigstens 0,15 pCt. zu gering angeschlagen sind, dass wir also wirklich durch die erhöhte Stauung auch einen erhöhten Verbrauch an Eiweiss im capillaren Gefässsystem beobachten können.

Wir kommen also nach den vorliegenden Untersuchungen zu folgenden Ergebnissen. Das arterielle und meist auch das capillare Blut enthält mehr Eiweiss wie das venöse. Dieser Unterschied ist zum Theil durch eine Abgabe an Eiweiss zu erklären, der im capillaren System vor sich geht. $O b$ dieser Verbrauch ein constanter ist, resp. wovon er im einzclnen abhängig ist, lässt sich nach meinen Untersuchungen nicht sagen. Jedoch dürfte es von Interesse sein, diese Frage weiter zu verfolgen. Weiter habe ich im Einklang mit früheren Untersuchern feststellen können, dass der Eiweissgehalt bei normalen Menschen Schwankungen unterliegt, die sich jedoch in ziemlich feststehenden Grenzen halten, und die Werthe von $7,42-9,13$ pCt. Eiweiss nicht überresp. unterschreiten.

Bei Herzinsufficienzen, seien sie bedingt durch Klappenfehler oder andere Lrkrankungen der Kreislauforgane, findet bisweilen, und zwar nur dann cine Herabsetzung des Eiweissgehaltes des Serums statt, wenn sie klinisch erkenntlich decompensirt sind. Ich möchte noch ganz besonders betonen, dass selbst ganz hochgradige Decompensation nicht unbedingt eine Erniedrigung des Eiweisswerthes herbeizulühren braucht, sondern dass wir hierbei eventuell ganz normale Verhältnisse beobachten können. Andere accidentelle Momente, wie z. B. die hochgradige Pleuritis in Fall No. 3 brauchen keine Veränderungen auf das Sinken des Eiweissgehaltes auszuüben. Der einzige Factor, der für diese Herabsetzung der Concentration verantwortlich zu machen ist, ist die erlahmende Herzkraft. Dic relativ hoch liegenden Eiweisswerthe im capillaren System — die ja noch durch Beimengung mit Zellsaft verdünnt worden sind - lassen sich gegenüber den Werthen des Venenblutes dadurch crklären, dass bei der verlangsamten Circulation die Abgabe von Eiweiss in dem capillaren System intensiver ist, vielleicht in Folge der veränderten Capillarwanddurchlässigkeit. Dass der Unterschied im Versuch 6 so hoch liegt, ist vielleicht dadurch zu erklären, dass eine erhöhte Diffusion von Gewebsflüssigkeit in die capillaren Gefässe stattgefunden hat, wodurch eben das venöse Serum in seiner Concentration so stark herabgesctzt worden ist. Solche hochgradigen Verdünnungen sind natürlich beim normalen Mensehen ausgeschlosen.

\section{Verhalten des Fiweissgehaltes des Blutes bei Nierenkrankheiten.}

Die erston Blutuntersuchungen bei Nephritiden wurden von Gregory, Bostock und Christison (16) ausgeführt und ergaben eine starke Verminderung der festen Stoffe des Scrums. Ltwas später wurde dann von Schmidt (17) bei einigen Fällen von Nephritis eine Vermehrung der Blut- 
flüssigkeit, also ein Volumen auctum im allgemeinen und eine Verdünnung des Serums im besonderen gefunden. Spätere Forscher, u. a. Frerichs (15), ermittelten eine Wasserzunahme des Blutes, also eine echte Hydrämie. Nach den Angaben von Grawitz (11) richtet sich die Blutzusammensetzung bei Nephritiden ganz nach der Art der pathologischen Veränderungen des Organes, mag es sich nun um interstitielle oder parenchymatöse Formen handeln. Nach seiner Ansicht ist ferner der Grad der Erkrankung von Bedeutung, und schliesslich spielt die wesentlichste Rolle bei der Herabsetzung der Blutconcentration das Vorhandensein von Oedemen. Bei der parenchymatösen chronischen Form soll eine Herabsetzung der Concentration des Gesammtblutes, welche mancherlei Schwankungen unterworfen sei, auftreten. Bei der chronisch interstitiellen Form unterscheidet er zwei Stadien. Die leichte Erkrankung der Niere macht keine, von der Norm besonders abweichende Erscheinungen im Blute wegen der compensatorisch eintretenden vermehrten Herzarbeit. Dagegen tritt bei schwerer Erkrankung eine starke Concentrationserniedrigung ein, da bei der fortschreitenden Entzündung eine gewaltige Inanspruchnahme der Herzkraft eintritt, die schliesslich versagt, sodass damit "das Symptomenbild der gestörten Compensation bei allgemein zunehmendem Marasmus" auftritt. In Folge dieser Kreislaufinsufficienz müssen hier dann natürlich ähnliche Verhältnisse, wie sie früher beschrieben worden sind, geschaffen werden. Nach den Untersuchungen von Askanacy (19) ist das ausschlaggebende Moment bei der Veränderung des Blutserums das Auftreten von Oedemen. Während er nämlich bei Nephritiden ohne Oedeme fast regelmässig normalen Serumbefund erheben konnte, fand er bei dem Vorhandensein von hydropischen Zuständen den Wassergehalt bei fast allen untersuchten Fällen erhöht und zwar bis über 94 pCt. Ein Parallelismus zwischen der Stärke der Serumverdünnung und dem Grade der Oedeme war nicht zu constatiren, so dass "zuweilen ein Patient mit geringem Anasarka ein wässerigeres Blutserum hatte, als ein anderer mit starken Oedemen". Dagegen fand er bei Zu- resp. Abnahme der hydropischen Erscheinungen ein umgekehrt proportionales Verhalten der Concentration des Serums. Mit diesen Ergebnissen bestätigt Askanacy die Befunde früherer Autoren, wie Peiper (20), Menicanti (21), Hammerschlag (22), von Jaksch (23), Stintzing und Gumprecht (15). Weiter nimmt er auf Grund seiner Untersuchungen an, dass die Eiweissausscheidung im Urin eine grosse Rolle bei der Serumconcentration spielt. Auch die Wasserausscheidung, d. h. die Menge des täglichen Urins, soll von nicht zu unterschätzender Bedeutung sein. Interessante Beobachtungen machte Reiss (24) bei vergleichenden Untersuchungen der Blutconcentration und des Körpergewichts bei Säuglingen. Er fand nämlich, dass Gowichtszunahme, beruhend auf Wasseretention im Körper, eine Verringerung, Gewichtsverlust, in Folge von Wasserabgabe ein Steigen des Eiweissgehaltes des Serums, d. h. also eine Erniedrigung resp. Erhöhung der Concentration bewirke. Wenn wir diese Erfahrungen von Reiss auf die hydropischen Formen der Nephritis beziehen, so erscheint es von vornhercin klar zu sein, dass wir bei auftretenden Oedemen, die natürlich auf Wasserretention im 
Körper beruhen, ein Sinken des Eiweissgchaltes im Blutserum beobachten müssen. Dieses hydrämische Verhalten des Blutes kann nun wiederum die Entstehungsmöglichkeit der Oedeme erleichtern, woil die durch toxische Einflüsse alterirten Gefässe dem Uebertreten eines verdünnten Blutserums in die Gewebe natürlicher Weise weniger Widerstand entgegensetzen werden, als einem hocheoncentrirten Serum.

In den nachfolgenden Versuchen nehmen wir eine andere Eintheilung der Nophritiden vor, unter functionellen Gesichtspunkten. Es ist von geringerem klinischen Interesse, ob das Parenchym der Niere oder ihr interstitielles Gewebe in einer bestimmten patbologischen Weise verändert sind, sondern in erster Linie die Veberlegung, in wie weit ist die Function, die physiologische Arbeitsfähigkeit des Organes geschädigt. Bei der Niere wissen wir, dass einerseits die Blutgefässe besonders in Gestalt der Glomeruli und andererseits die Harnkanälchen ganz verschiedene Filtrations- resp. Secretionsarbeiten zu leisten haben. Während nämlich die Glomeruli die flüssigen Bestandtheile, in erster Linie also das Wasser, aus dem Gelässsystem austreten lassen, werden durch Secretion der Tubulus-Zellen die meisten anderen Harnsubstanzen ausgeschieden. Um nun zu erfahren, welcher dieser beiden Factoren bei der Nierenarbeit geschädigt ist, haben Schlayer und T'akayasu (25) eine Reihe von Untersuchungen angestellt, indem sie bei experimentell erzeugten Schädigungen einerseits der Glomeruli, andererseits der Tubuli die Ausscheidungsverhältnisse bestimmter Körper prüften. Von körpereigenen Substanzen verwandten sio Kochsalz und Wasser, von körperfremden Milchzucker und Jodkali bei ihren Untersuchungen. Das Ergebniss dieser Versuche war: "Zerstörung der Tubuli hat verschlechterte Ausscheidung von Kochsalz und Jodkali zur Folge, sind aber die Nierengefüsse geschädigt, so wird der Milchzucker verlängert ausgeschieden. Die Grösse der Wasserausscheidung erlaubt kein sicheres Urtheil über den Zustand einer Niere, nur die nephritische Oligurie ist ein sicheres Zeichen schwerer Nierengefüsschädigung. " Die Ausscheidungszeit beträgt für 1 oder $2 \mathrm{~g}$ Milehzucker beim normalen Menschen im Maximum 5 Stunden. Hierbei ist von Wichtigkeit, dass krankhafte Veränderungen anderer Organe die Ausscheidungszeit nicht becinflussen. Nur bei schweren Herzinsufficienzen wird diese Zeitangabe unzuverlässig. Die Ausscheidungszeit für 0,5 bis $1 \mathrm{~g}$ Jodkali beträgt im Höchstfalle 55 bis 60 Stunden. Diese Erfahrungen von Schlayer und Takayasu veranlassen mich, die Eiweissuntersuchungen des Blutserums nach den Gesichtspunkten der functionellen Schädigung cincrseits der Nierengelässe, andererseits der Harnkanälchen vorzunehmen.

Bevor ich auf die Ergebnisse dieser Untersuchungen näher eingehe, möge es mir gestattet scin, einen Fall von acuter Nephritis in Folge von Sublimatvergiftung zu erwähnen. Die Patientin hatte am 26.4.1911, morgens, 3 Angerer'sche Pastillen ì 1 g genommen. Nach $21 / 2$ Stunden trat Erbrechen cin, das bis zum Tode in unverminderter Stärke fortbestand. Gleichzeitig bestand von dem Augenblick der Intoxication an totale Anurie. Auch wurde später bei der Section keine Urinflüssigkeit in der Blase gefunden. Als Patientin um 4 Uhr in die Klinik einge- 
liefert wurde, fand sich ein refractometrischer Index von 1,353196 oder ein Eiweissgehalt von 10,007 pCt. im Serum des capillaren Blutes. Dieser Werth sank dauernd am nächsten Tage bis auf 1,351283, entsprechend einem Eiweissgehalt von 8,9006 pCt, und im venösen Blute auf 1,350913, einem Eiweissgehalt von 8,6866 entsprechend. $\Lambda \mathrm{m}$ 23. 4. war der Werth noch weiter gesunken, und zwar auf 1,350728 oder, im Procentgehalt des Eiweisses angegeben, auf 8,5796. Von jetzt ab stieg die Concentration des Serums andauernd, bis sie am 30. 4., mittags 12 Uhr 31 Min. den höchsten beobachteten Werth von 1,355474 erreichte, was einem Eiweissgehalt von 11,334 pCt. entspricht. Dieses Verhalten können wir uns nur so erklären, dass der zunächst sebr hochliegende Eiweissgehalt des Serums eine Verdünnung erfahren hat durch Resorption der vorhandenen Gewebsflüssigkeit in das Gefässsystem, oder dass ein Verbrauch von Eiweiss im Organismus eingetreten ist, der eben nicht ersetzt werden konnte, weil es unmöglich war, der Patientin Nahrung zuzuführen. Ich glaube, dass bei einem Erklärungsversuch nur diese beiden Factoren in Frage kommen. Durch den Verbrauch von Eiweiss allein würde sich bei dem dauernden Erbrechen, das eine Eindickung der Blutflüssigkeit und damit eine Concentrationssteigerung zur Folge haben muss, dieses Absinken des Eiweissgehaltes nicht erklären lassen. Dureh Resorption der Gewebsflüssigkeit in die Gefässe würde ja die Verdünnung erklärt werden können, aber es müsste ja bei dem dauernden Erbrechen der Kranken, das natürlich dem Organismus viel Wasser entzogen hat, eine beim normalen Menschen unmöglich vorhandene Menge von Gewebsflüssigkeit vorhanden gewesen sein, um eine Verminderung des Eiweissgehaltes von 10,0072 auf $\varepsilon, 5796$ pCt. herbeizuführen. Ich nehme deshalb an, dass neben der Resorption von Gewebsflüssigkeit, die eben ausgereicht hat, um den Flüssigkeitsverlust des Blutes in Folge des andauernden Erbrechens zu decken, ein Verbrauch von Eiweiss Hand in Hand gegangen ist. Mit dem Augenblick, wo der Zufluss von Gewebsflüssigkeit versiegte, sehen wir dann eine enorme Bluteindickung einsetzen, die sich durch den abnorm hohen Eiweissgehalt von 11,334 documentirt. Dieser Fall zeigt uns mit fast absoluter Sicherheit, dass der Eiweissgehalt neben relativen Schwankungen auch absoluten Werthveränderungen ausgesetzt ist, der nur durch einen Verbrauch von Eiweiss zu erklären ist, der, wie wir schon früher gesehen haben, im capillaren System vor sich gehen muss.

Bei den weiteren Untersuchungen von Nephritiden hat sich nun ein ähnliches Verhalten des Eiweissgehaltes des Blutserums im capillaren System im Vergleich zu dem des venösen gezeigt, wie in früheren Versuchen bei normalen Menschen. Wir fanden nämlich bisweilen ein Ueberwiegen der Concentration im venösen, bisweilen im capillaren Serum. Letzteres Verhalten, das wir bei normalen Menschen als die gewöhnliche Erscheinung betrachten könnten, fand sich bei unseren Fällen relativ selten, aus dem einfachen Grunde, weil hier in Folge der Oedeme eine Verdünnung des capillaren Serums mit Gewebsflüssigkeit bei der Blutentnahme eintreten musste. Je hochgradiger die Oedeme waren, desto grösser wurden die Unterschiede der Concentration zu Ungunsten 
des capillaren Serums. Folgende Versuche, die zunächst nach rein klinischen Erscheinungen zusammengestellt sind, mögen dies bestätigen. (s. nebenstehende Tabelle VIII).

Wir sehen also aus diesen Versuchen, dass der Eiweissgehalt des Blutserums bei chronischen Nephritiden durchaus normal sein kann. Selbst das Vorhandensein von Oedemen, wie im Versuch 3, braucht nicht immer eine Hydrämie hervorzurufen. Meistentheils tritt allerdings mit hydropischen Zuständen eine Concentrationserniedrigung ein, die jedoch keinen Parallelismus zu der Stärke der Oedeme formuliren lässt. Dass die Eiweissausscheidung, wie Askanazy annimmt, einen grossen Einfluss auf die Concentration des Serums ausübt, scheint wenigstens bei den chronischen Formen der Nephritis nicht der Fall zu sein. Denn in Versuch 4 sehen wir eine erhebliche Verminderung des Eiweissgehaltes des Serums, ohne dass jrgend nennenswerthe Eiweissverluste im Urin nachweisbar waren. Dagegen finden wir in Versuch 3 bei einer deutlichen Albuminurie ein ganz normales Verhalten der Eiweissconcentration. Wie die Eiweissausscheidung im Urin bei acuten Nephritiden auf den Eiweissgehalt des Serums wirkt, bin ich nicht in der Lage angeben zu können. Ich bin, gerade wie Grawitz, der Ansicht, dass die Verminderung des Eiweissgehaltes weniger auf die Nephritis zu beziehen ist - wenigstens bei den hier beobachteten chronischen Formen - als vielmehr auf eine secundäre Herzinsufficienz, da wir bei geringen Graden von Nephritis, bei denen eine Compensation durch den Kreislauf eintritt, ganz normale Serumconcentration beobachten konnten.

Was nun die Eiweissconcentration bei Schädigung der Glomeruli, d. h. des vasculären Systems einerseits und der Tubuli andererseits betrifft, so habe ich sowohl bei der Verlängerung der Jodausscheidung von über 60 Stunden, wie auch bei Formen von Nephritis, die bei normaler Jodausscheidung mit Oligurie einhergingen, wo wir also eine Schädigung des Gefässsystems annehmen müssen, keine Verschiedenheit in der Concentration des Serums feststellen können (s. nebenstehende Tabelle IX).

Wir sehen also, dass auch nicht die Schädigung der Niere in einer bestimmten Form einen wesentlichen Einfluss auf das Verhalten der Concentration des Serums auszuüben vermag. Nur dann, wenn wir uns von dem Vorhandensein von Oedemen, die wohl in erster Linie als Decompensationserscheinungen des Kreislaufes zu betrachten sind, überzeugen konnten, sehen wir, dass eine Abnahme der Serumconcentration eintritt.

Die Unterschiede, die wir im Eiweissgehalt des capillaren Serums und dem Serum des Venenblutes gefunden haben, beruhen, wie schon anfangs erwähnt wurde, auf einer Verdünnung des capillaren Blutes, die bei dem Einstich in die Fingerbeere eintritt. Je hochgradiger die Oedeme bei Nephritis sind, desto mehr Gewebsflüssigkeit wird bei der Blutentnahme dem ausfliessenden Blute beigemischt, sodass wir recht beträchtliche Unterschiede in dem Eiweissgehalt des venösen und capillaren Serums vorfinden können. In Fall No. 5 und 6 sehen wir das normale Verhalten, nämlich, dass das Serum des capillaren Blutes höhere Eiweiss- 
Eiweissgehalt des capillaren und venōsen Blutserums.

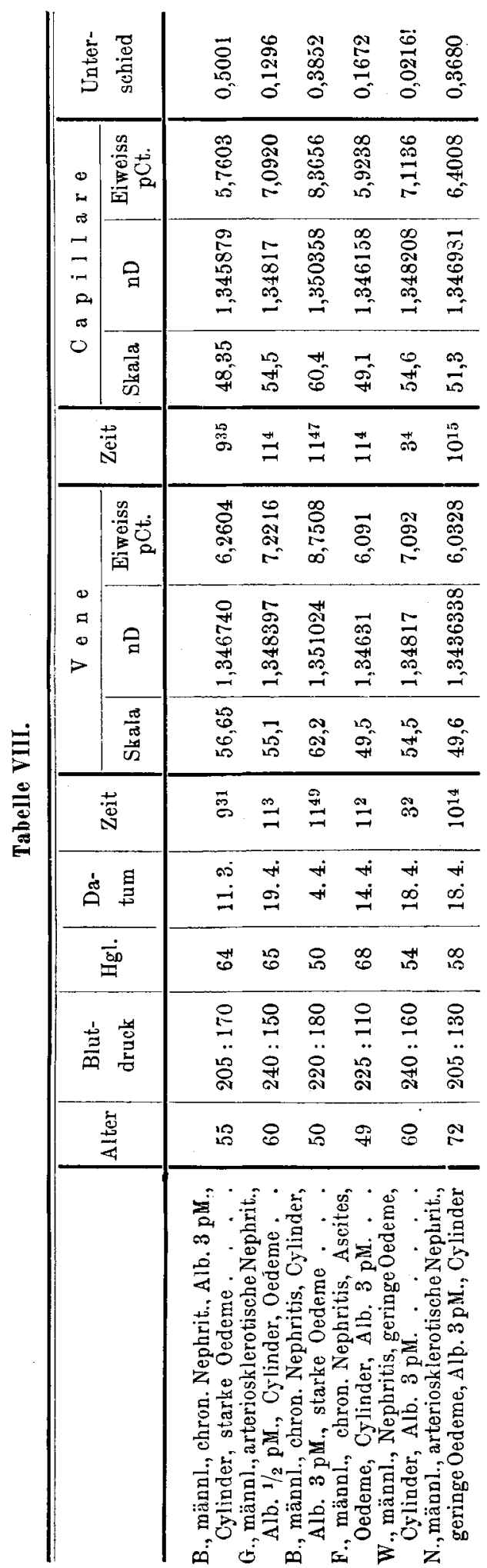

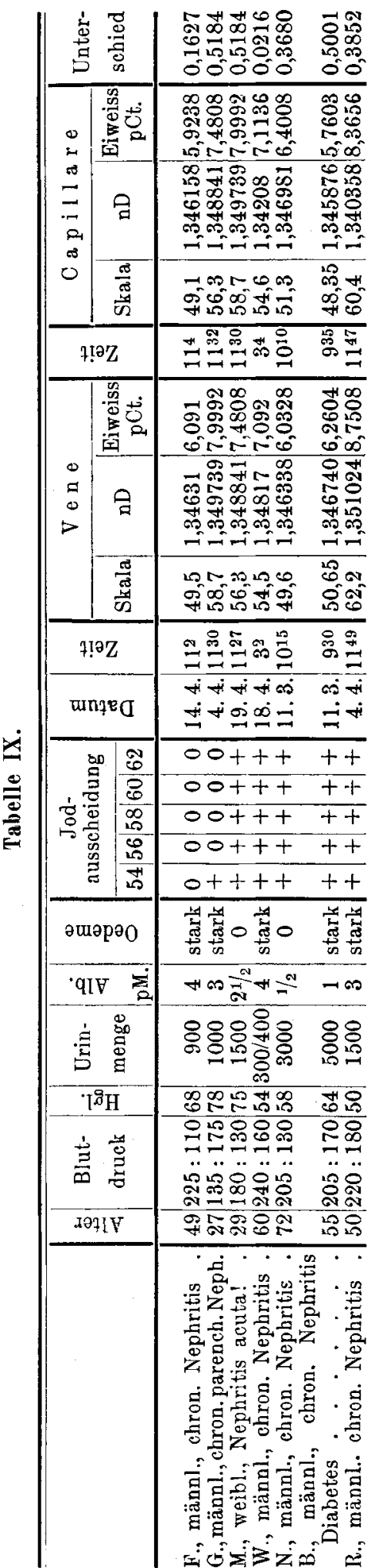

11 * 
concentration aufweist, als das der Vene. Wir haben in diesen beiden Fällen gar keine oder nur ganz geringe Oedeme feststellen können. Neben dieser Beimengung von Gewebsflüssigkeit beruhen diese besprochenen Unterschiede wohl noch darin, dass wir bei der Blutentnahme in der Pẹripherie nicht wissen können, ob wir hauptsächlich arterielle oder venöse Gefässe anschneiden. Je mehr venöse Gefässe getroffen werden desto mehr wird sich der gefundene Werth dem des Venenserums nähern resp. ihn unterschreiten in Folge der Vermengung mit Gewebsflüssigkeit. Je mehr arterielles Blut hingegen aus dem gesetzten Einstich hervorquillt, desto grösser werden die Unterschiede gegenüber dem Venenserum ausfallen.

\section{Verhalten des Eiweissgehaltes des Serums bei Tuberkulose.}

Die Zusammensetzung des Blutes bei der Lungentuberculose ist bei der Häufigkeit der Krankheit von zahlreichen Beobachtern untersucht worden. Zuerst haben Becquerel und Rodier (14), die, wie schon früher erwähnt, ausgedehnte Blutuntersuchungen vornahmen, auch die Lungentuberculose in den Kreis ihrer Untersuchungen gezogen. Sie fanden, auch bei vorgeschrittener Erkrankung, für das specifische Gewicht normale Werthe. Später fand Oppenheimer (27) ebenfalls normale Werthe für den Blutfarbstoff wie für die Zahl der rothen Blutkörperchen. Dagegen kunnte Neubert (28) 1889 bei einem grossen Theil seiner Phthisen eine Herabsetzung der rothen Blutkörperchen constatiren. Stintzing und Gumprecht (15) fanden eine erhebliche Zunahme des Wassergehaltes in dem Blute von Phthisikern. Hammerschlag (22) constatirte dagegen nur dann cine Erniedrigung der Concentration, wenn die Erkrankung mit hochgradiger Kachexie einherging. Grawitz fand bei seinen Untersuchungen sehr starke Differenzen, sodass man „nicht schlechtweg von dem Blute bei Tuberculose" sprechen könne. Er theilt deshalb im Anklang an die Strauss'sehen Untersuchungen seine Befunde in drei Phasen ein. Während er bei incipienter Phthise ohne Cavernensymptome Herabsetzung der Trockensubstanz constatiren konnte, bot sich bei chronischer Form mit Cavernensymptomen das unerwartete und überraschende Bild einer gganz normalen Blutzusammensetzung". Bei den ganz progressen Formen mit hektischem Fieber fand er dann wieder eine bedeutend herabgesetzte Concentration des Blutes. Die Strauss'schen Untersuchungen (29) haben dasselbe Verhalten für die Znsammensetzung des Gesammtblutes ergeben. Auch für den Eiweissgehalt fand er in dem dritten Stadium bedeutend herabgesetzte Werthe, aber nur dann, wenn die Patienten dauernd an Fieber litten. Meine Versuche, die sich auf incipiente Phthise beziehen, sind angestellt worden bei Patienten der Vorstation, bei denen in Folge sicheren Lungenbefundes (Percussion, Auscultation, Röntgenbild) eine Heilstättenbehandlung indicirt erschien. Bei diesen Tuberculosen, die der ersten Gruppe von Grawitz entsprechen, haben sich, wie die nebenstehende Tabelle $\mathrm{X}$ zeigt, ganz normale Werthe des Eiweissgehaltes constatiren lassen.

Wir sehen also, dass wir bei diesen incipienten Formen einen ganz normalen Eiweissgehalt rorfinden, der allerdings dadurch auffällt, dass 
Eiweissgehalt des capillaren und venösen Blutserums.

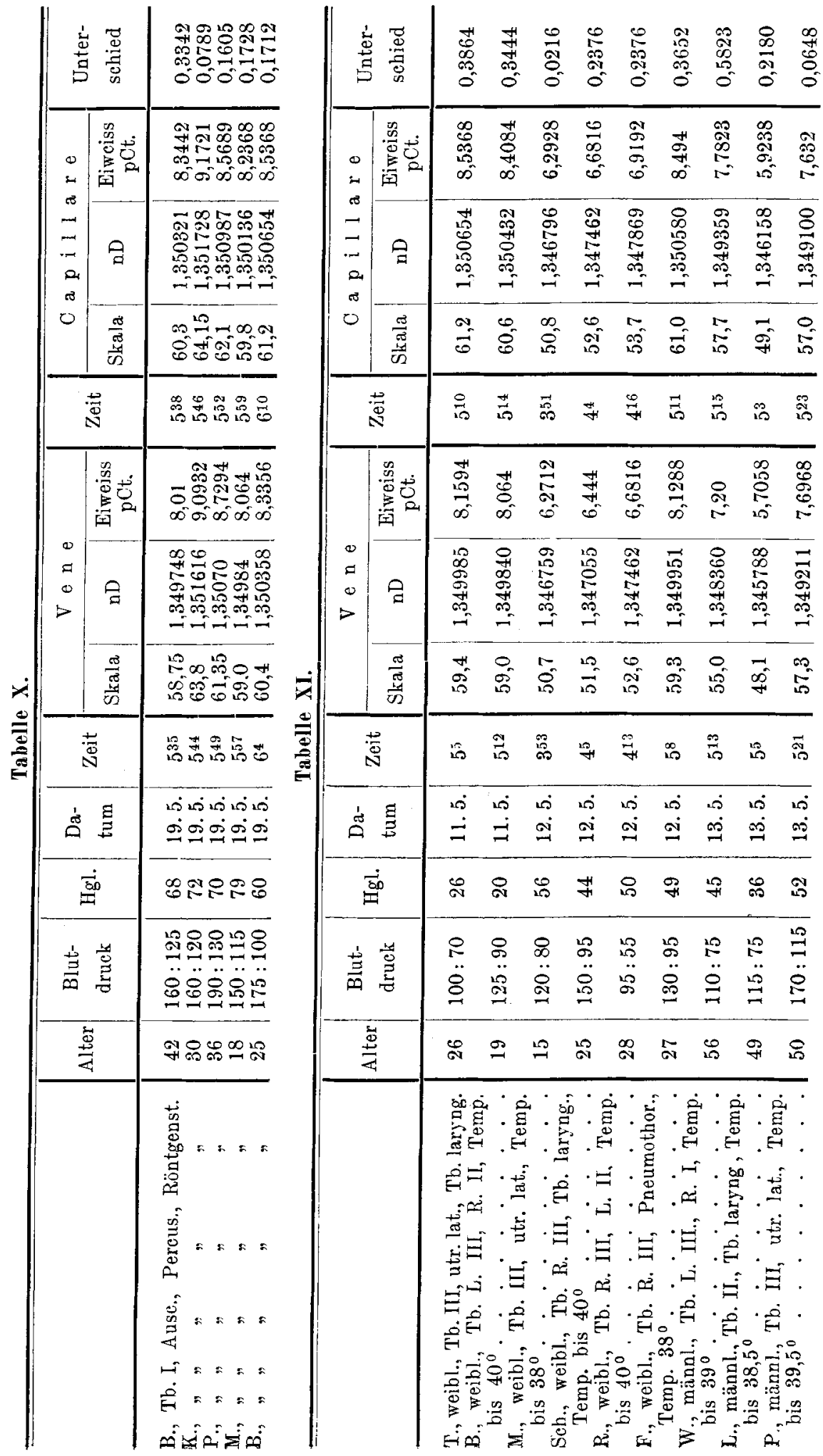


die Werthe durchweg boch liegen. Auch die Unterschiede zwischen dem Gehalt des venösen und capillaren Blutes entsprechen durchaus der Norm. Bei den Formen, die Strauss zu der zweiten Gruppe, d. h. chronische Tuberculose mit geringem Fieber, rechnet, haben sich ganz dieselben Werthe ergeben, wie sie Strauss und Grawitz beobachten konnten. Der Eiweissgehalt sowohl im venösen wie im capillaren Blute entsprach ganz den Werthen, die bei normalen Menschen festgestellt werden kounten. Was nun die Phthisen 3. Grades anbelangt, so sind die Resultate in der umstehenden Tabelle XI zusammengefasst.

Wir sehen aus diesen Werthen, dass bei schwerer Erkrankung der Lungen keine Einheitlichkeit in dem Gehalt des Blutserums an Eiweiss besteht. In ca. der Hälfte der Fälle finden wir einen als normal zu bezeichnenden Eiweissgehalt, obgleich wir es zum Theil mit moribunden Menschen zu thun haben. Es ist dies Resultat um so überraschender, weil die Nahrungsaufnahme bei allen Patienten recht gering war. Vielleicht ist eine Erklärung dadurch gegeben, dass die meisten von ihnen an recht profusen Schweissen leiden, die natürlich eine Concentration, und damit auch eine Erhöhung des Eiweissgehaltes herbeiführen müssen. Jedoch ist diese Erklärung deshalb nicht einwandsfrei, weil wir bei den anderen Fällen, wo eine deutliche Herabsetzung des Eiweissgehaltes zu constatiren war, dieses Moment der Wasserabgabe ebenfalls in Rechnung zu ziehen haben. Vielleicht besteht die Ansicht Grawitz's, dass wir bei einzelnen Formen der schweren Phthisen eine Oligaemia vera vor uns haben, zu Recht, wodurch wir uns das Verhalten der normalen Eiweissconcentration einigermassen erklären könnten. Auffallend ist allerdings das Verhalten des Hämoglobins in den ersten beiden Fällen, wo wir bei normalem Eiweissgebalt eine abnorm niedrige Beschaffenheit des Blutfarbstoffes vorfinden, gegenüber anderen Patienten mit herabgesetztem Eiweissgehalt und relativ hochliegendem Hämoglobin.

Die recht erheblichen Unterschiede im Eiweissgehalt des venösen und capillaren Blutes dürften bei oberflächlicher Beobachtung sich dadurch erklären lassen, dass alle diese Kranken starken Schweissausbrüchen und damit einem erhöhten Wasserverlust in den Capillaren ausgesetzt sind. Je hochgradiger diese Flüssigkeitsentziehung ist, desto deutlicher müsste dann der refractometrische Werth des Capillarblutes in Folge der Wasserentziehung steigen. Hiergegen ist einzuwenden, dass es nicht einzusehen ist, dass das Blut in der Armvene, das ja doch zum grössten Theil aus den Gefässen der Peripherie besteht, einen tieferen Werth zeigen soll als das Serum der Capillaren. Es müsste ja nach einer vorhergehenden Wasserentziehung vielmehr in seiner Concentration gestiegen sein. Deshalb ist daran zu denken, ob der Unterschied bedingt sein könnte durch einen intensiveren Verbrauch von Eiweiss, der in Folge des erböhten Nahrungsbedürfnisses der durch die krankhaften Prozesse in ihrer Ernährung geschädigten Zellen erheblicher sein dürfte als beim normalen Menschen.

Dass- unsere Resultate nicht immer dieselben Werthunterschiede in dem Eiweissgehalt des venösen und capillaren Serums ergeben, liegt, 
wie schon früher ausgeführt wurde, an der Unmöglichkeit, die Fehlerquellen auszuschalten, die bei der Blutentnahme aus dem capillaren System unterlaufen können. Sie liegen einerseits in der Unberechenbarkeit der Verdünnung des Blutes mit Gewebsflüssigkeit, deren Grösse ganz von dem Wasserreichthum des Gewebes abhängt, und andererseits in der Möglichkeit, dass wir bei dem Einstich mehr venöse resp. arterielle kleinste Gefässe eröffnen.

\section{Literaturangaben.}

1. Strubell, Verhandlungen des 18. Congresses für innere Medicin. Wiesbaden 1900.

2. Grober, Centralbl. f. innere Med. 1900.

3. Reiss, Inaug.-Diss. Strassburg 1902.

4. Derselbe, Beiträge zur chemischen Physiologie und Pathologie. Bd.4. H.3u.4.

5. Derselbe, Arch. f. exp. Pathologie u. Pharm. Bd. 53.

6. Derselbe, Verhandlungen der 76. Versammlung Deutscher Naturforscher und Aerzte. Breslau 1904.

7. Strauss, Therapie der Gegenwart. 1903.

8. Strauss und Chajes, Zeitschr. f. klin. Med. Bd. 52 .

9. Reiss, Zeitschr. f. Elektrochemie. No. 37.

10. von den Velden, Zeitschr. f. exp. Pathologie u. Therapie. 1909.

11. E. Grawitz, Klinische Pathologie des Blutes.

12. Loewy, Ueber Veränderungen des Blutes unter thermischen Einflüssen. Berliner klin. Wochenschr. 1896. No. 41.

13. Chiarolanza, D. Arch. f. klin. Med. 1908. Bd. 94.

14. Becquerel und Rodier, Untersuchungen über die Zusammensetzung des Blutes usw. Gitirt n. E. Grawitz.

15. Stintzing und Gumprecht, Deutsches Arch. f. klin. Med. Bd. 15.

16. Gregory, Bostok, Christison, citirtn. Askanazy. D.Arch.f.klin. Med. Bd.59.

17. C. A. Schmidt, Zur Charakteristik der epidemischen Cholera. Leipzig 1850.

18. Frerichs, Die Bright'sche Nierenkrankheit und deren Behandlung. Braunschweig.

19. A skanazy, D. Arch. f. klin. Med. Bd. 59 .

20. E. Pөiper, Centralbl. f. klin. Med. Bd. 18.

21. Menikanti, D. Arch. f. klin. Med. Bd. 50 .

22. Hammerschlag, Zeitschr. f. klin. Med. Bd. 20.

23. v. Jaks.ch, Zeitschr. f. klin. Med. Bd. 23.

24. E. Reiss, Jahrbuch für Kinderheilkunde. Bd. 70.

25. Schlayer und Takayasu, D. Arch. f. klin. Med. Bd. 101.

26. Magnus, In Oppenheimer's Handbuch der Biochemie.

27. Oppenheimer, Deutsche med. Wochenschr. Bd. 89. No. 42-44.

28. Neubert, citirt n. E. Grawitz.

29. Strauss, Zeitschr. f. klin. Med. 1894. Bd. 24. 